\title{
Goals are Not Enough: Building Public Sector Capacity for Chronic Disease Prevention
}

\author{
Heather Manson, MD, MHSc, ${ }^{1}$ \\ Terrence Sullivan, $\mathrm{PhD},{ }^{2}$ \\ Phat $\mathrm{Ha}, \mathrm{MPH},{ }^{3}$ \\ Christine Navarro, MD, MSc, ${ }^{4}$ \\ José M. Martín-Moreno, MD, PhD, DrPH
}

\begin{abstract}
The rising burden of non-communicable diseases (NCDs) challenges the public health sector to develop, support and implement effective interventions to reduce this global epidemic. The United Nations has responded with a global action plan that includes goals and voluntary targets for the prevention and control of NCDs. However, setting goals is not enough. To achieve meaningful outcomes, governments must act and invest to improve key enabling capacities. Political and other public sector leadership at every jurisdictional level is needed to implement health-in-allpolicies initiatives and to measure progress against set objectives, while technological and human resources for health should be developed with a focus on public health competencies. NCD surveillance and monitoring systems must be strengthened to ensure a rapid policy cycle, and public health research capacity should be built up, not only to assess the NCD challenge, but also to develop, adapt and apply new techniques and tools with the participation of decision-makers. Government and civil society partnerships are increasingly important, especially at the local level, to build multipliers, foster equity, and meet the needs of populations at risk. Given the magnitude of the NCD burden, prevention and management approaches require growth and alignment of innovative financial supports to reduce direct health
\end{abstract}

\footnotetext{
${ }^{1}$ Chief, Health Promotion, Chronic Disease and Injury Prevention, Public Health Ontario, Canada.

${ }^{2}$ Professor, Institute of Health Policy Management and Evaluation, University of Toronto, Canada.

${ }^{3}$ Research Coordinator, Public Health Ontario, Canada.

${ }^{4}$ Public Health and Preventive Medicine Resident, University of Toronto, Canada.

${ }^{5}$ Professor, Department of Preventive Medicine of the Faculty of Medicine, and INCLIVA Biomedical Research Institute, University of Valencia, Spain.
}

Corresponding Author Contact Information: Heather Manson at Heather.Manson@ oahpp. ca; Chief, Health Promotion, Chronic Disease and Injury Prevention, Public Health Ontario, Canada. 
expenditures and lost wages while increasing productivity. Lastly, making progress on NCDs requires a range of integrated, programmatic, health communications activities in addition to sound public policies that cross the health and non-health care sectors.

Key Words: Chronic disease, capacity building, public sector, leadership

Recommended Citation: Manson H, Sullivan T, Ha P, Navarro C, Martín-Moreno, JM. Goals are not enough: building public sector capacity for chronic disease prevention. Public Health Reviews. 35: epub ahead of print.

\section{INTRODUCTION}

In 2010, non-communicable diseases (NCDs) caused 34.5 million deaths globally (about two-thirds of all deaths), mainly due to ischemic heart disease, stroke, cancer, chronic obstructive pulmonary disease, and diabetes. ${ }^{1}$ These figures represent a shift in the global burden of disease over the last two decades, with a rise in NCD-related deaths in persons over 40 years of age and a decline in childhood deaths from communicable disease. This is increasingly the case in low- and middle- as well as in highincome countries. ${ }^{1}$ Growth and aging of the world's population contribute to this epidemiologic transition, ${ }^{1}$ compounding the global impact of the leading NCD risk factors. In 2010, hypertension, tobacco use and alcohol were the most important contributors to the global disease burden; diets high in sodium, high body-mass index, and physical inactivity each accounted for more than three million deaths globally. ${ }^{2}$ The increase in illness and premature death due to NCDs inflicts a very high economic burden on health systems and society generally, including through pernicious losses in economic output. ${ }^{3,4}$

The impact of NCDs has increasingly influenced national and international health policy. With the 1986 Ottawa Charter for Health Promotion $^{5}$ as a basic framework, different global and regional strategies have been introduced to address $\mathrm{NCDs}^{6,7}$ and the related risk factors of tobacco use, ${ }^{8}$ unhealthy diet and physical inactivity, ${ }^{9,10}$ and alcohol use. ${ }^{11}$ In 2011, global commitment to reduce the burden of NCDs was reaffirmed at the United Nations General Assembly; a crucial tenet of the resulting political declaration was that governments have a primary responsibility to address the growing burden of NCDs. ${ }^{12}$ The recently endorsed WHO global action plan on NCDs set a vision as well as objectives and voluntary global targets for 2013 to $2020 ;{ }^{13}$ voluntary targets for member countries were also recommended (see Box 1). ${ }^{14}$ 


\section{Box 1}

WHO Voluntary Global Targets for the prevention and control of NCDs ${ }^{15}$

1) A $25 \%$ relative reduction in the overall mortality from cardiovascular diseases, cancer, diabetes, or chronic respiratory diseases.

2) At least $10 \%$ relative reduction in the harmful use of alcohol, as appropriate, within the national context.

3) A $10 \%$ relative reduction in prevalence of insufficient physical activity.

4) A $30 \%$ relative reduction in mean population intake of salt/sodium.

5) A 30\% relative reduction in prevalence of current tobacco use in persons aged 15+ years.

6) A $25 \%$ relative reduction in the prevalence of raised blood pressure or control of the prevalence of raised blood pressure, according to national circumstances.

7) A halt in the rise in diabetes and obesity.

8) Availability of drug therapy and counselling (including glycemic control) for at least 50\% of eligible people to prevent heart attacks and strokes.

9) An $80 \%$ availability of the affordable basic technologies and essential medicines, including generics, required to treat major non-communicable diseases in both public and private facilities.

However, goals, objectives and targets are not enough. To achieve the vision of "a world free of the avoidable burden of non-communicable diseases," ${ }^{15}$ governments and other stakeholders must invest in and develop the capacity and leadership to advance towards these goals. The objective of this paper is to describe the key enabling capacities required for effective NCD prevention, building on the framework for action on the primary prevention of chronic disease developed by the Chronic Disease Prevention Alliance of Canada (CDPAC) ${ }^{16}$ with supporting evidence from international sources, including reports from WHO and others.

\section{DISCUSSION}

Improving the health of the population through the prevention and control of non-communicable diseases (NCDs) requires an adequate and sustained program of effective interventions, adapted for the local context and implemented with sufficient reach to achieve outcomes. Programs should be comprehensive and extend beyond single risk factors and diseasebased perspectives. Key enabling capacities for the primary prevention of NCDs include leadership, both within and outside of the public sector; 
public health resources (including technological and human resources throughout the health and health care system); surveillance and monitoring; research and evaluation; knowledge mobilization infrastructures; sustained financial transfers; and, lastly, effective policy, program and health communications interventions.

\section{Enabling Capacity: Leadership on NCDs}

"Leadership in public health requires stretching the mind and soul in almost unimaginable ways."

Koh, H. Leadership in public health. ${ }^{17}$

Leadership —at the individual, organizational and system levels-is essential to address the burden of NCDs and its broader impact on society. Effective leaders are defined not only by their vision and goals, but also by their ability to create a legacy of progress through long-term strategies and inspiration to others.

Public health leadership is grounded in scientific evidence, social justice and a long-term view. Leaders must enable change by influencing the actions of others, including those with divergent perspectives. Some have called for the emergence of more "public health superheroes," capable of skilfully blending a deep understanding and passion for NCD prevention with personal humility and the will to create change that extends beyond the reach of any single organization. ${ }^{17,18}$ According to Koh, key leadership attributes for addressing complex phenomena such as NCDs include adopting a servant model of leadership (in which leaders are first and foremost public servants and enablers of their team), cultivating interdependence, accepting ambiguity, developing an ability to communicate and reframe, and creating a sense of community ${ }^{17}$ Brownson and colleagues identified leadership as a high priority administrative practice that is positively associated with outcomes linked to evidence-based decisionmaking. ${ }^{19}$ Effective leadership behaviors can also be assembled into four meta-categories: task-oriented, relations-oriented, change-oriented and external behaviours. ${ }^{20}$ There is also evidence that effective leaders manage change successfully, support innovation and the appropriate use of evidence, and employ participatory decision-making strategies. ${ }^{19}$

\section{Why is public sector leadership so important?}

At the most fundamental level, health is recognized as a basic human right; ${ }^{21-}$ ${ }^{23}$ moreover, only governments can ensure that this right is equally protected throughout society. Given their broad policy mandates and capacity to 
generate and deploy resources, governments are uniquely positionedperhaps even morally compelled - to lead on interventions designed with sufficient reach and scale to achieve population-level outcomes. Moreover, the economic impact of NCDs threatens to reduce governmental capacity to meet other (non-health) development goals and is thus a key driver for action across sectors. ${ }^{3}$ Through the use of policy and regulatory tools, program funding and convening, governments launch initiatives and coordinate the collective efforts of society, including at the community and clinical level. ${ }^{24}$ The 2011 UN High-level meeting on NCDs, ${ }^{12}$ the WHO global action plan $2013-2020,{ }^{13}$ and two WHO global strategies ${ }^{9,11}$ also emphasize the "primary steering and stewardship" role that government must play to ensure that multi-sectoral partnerships address goal-setting, resource allocation and funding. ${ }^{14}$

\section{Attributes of effective leadership}

Leadership at all levels. Effective leadership is required from all levels of government-local, regional, national and international-including leadership from the executive branch. ${ }^{8,11}$ Indeed, the NCD Alliance considers enhanced political leadership and commitment the most important outcome of the 2011 UN High-level meeting on NCDs. ${ }^{25}$ However, the mere presence of a division or unit to address NCDs within government is insufficient; if governments are unable to mobilize for action on NCDs, there is a real risk of failure in program implementation. ${ }^{26}$ Even in developed countries such as the U.S., questions have arisen with regard to the effectiveness of past public health programs, and decision-makers have been challenged to devise new strategies to improve performance. ${ }^{27}$

Leadership from outside the formal health sector also plays a role. Philanthropic bodies such as the Bill and Melinda Gates Foundation, ${ }^{28}$ Cancer Research UK, ${ }^{29}$ and many other voluntary and charitable organizations have been instrumental in shaping research and policy agendas where they are active. ${ }^{30}$ Professional and scientific societies, schools of public health, patient and advocacy groups, and other collectives also exercise vital leadership to support research excellence, service quality, patient empowerment and other complementary aspects of a comprehensive disease control effort. Lastly, public-private partnerships, such as text 4 baby, ${ }^{31}$ provide innovative models for horizontal leadership. In this mobile phone service for pregnant women, no single stakeholder stands out as steering the initiative; rather, each partner, including government agencies, local NGOs and private companies, has contributed to provide quality health information with rapid uptake, including among hard-to-reach population segments. ${ }^{32}$ 
Accounting for health in all policies. Governments that consider the impact on health during the policy-making process promote coherence between sectors (including non-health sectors) and are well positioned to tackle the NCD burden. This "whole-of-government" approach is recommended in many WHO strategies, addressing issues such as tobacco control ${ }^{88}$ diet and physical activity, ${ }^{9}$ and alcohol. ${ }^{11}$ The integration of health in all policies is gaining traction, with country surveys showing a moderate increase of integrated policies and disease- or risk factor-specific policies between 2000 and $2010 .^{33}$ The WHO national capacity assessment showed that $86 \%$ of countries depend on partnerships or collaborations to prevent and control NCDs; however, although most countries (76\%) have collaborations in the form of a cross-departmental or ministerial committee ${ }^{34}$ competing or divergent priorities and values can work against such partnerships. ${ }^{33}$

\section{Enabling Capacity: Surveillance and Monitoring}

"Public health surveillance is the ongoing, systematic collection, analysis, interpretation, and dissemination of data regarding a healthrelated event for use in public health action to reduce morbidity and mortality and to improve health."

German, RR. Updated guidelines for evaluating public health surveillance systems. ${ }^{35}$

Why are surveillance and monitoring capacities important?

All countries need dynamic, institutional processes that measure progress towards national and international targets for NCDs. ${ }^{13}$ Monitoring systems should be transparent, fostering values of equity and social solidarity. ${ }^{36}$ Independent national health commissions and international expert groups or multi-agency task forces can support this role. ${ }^{25}$ Well-functioning surveillance systems are essential to public health, providing accurate data on population health status, their exposure to risk and the presence of protective factors to help inform policy and program development. These systems should encompass the entire life span and provide actionable data for sub-populations at multiple levels (e.g., community, regional and national)..$^{14,24}$

Attributes of an effective surveillance and monitoring system

Ideal surveillance and monitoring systems are coordinated, comprehensive, connected, complete, valid, accessible and responsive. ${ }^{37}$ Monitoring should 
include demographic and socioeconomic characteristics of the population, risk factors and exposures, health resources, processes and outcomes, determinants of health, as well as policies and programs that affect health and the health system. ${ }^{13,37}$ By connecting data collection and analysis, health authorities will be better equipped to identify emerging trends, set local priorities, evaluate the impact of interventions, and address health inequities.

The need to improve measurement systems for NCDs was recently affirmed by the $\mathrm{UN}^{38}$ and $\mathrm{WHO},{ }^{13}$ which advise countries to invest in national surveillance and monitoring systems that integrate routine monitoring and special surveys into health information systems. These recommendations reflect the present inadequacy of NCD surveillance systems in terms of both completeness and validity. ${ }^{26}$ While most countries employ basic surveillance and monitoring programs for disease and risk factors, more sophisticated systems may be lacking (see Box 2).

\section{Box 2}

In a 2009-2010 survey of 23 countries worldwide with high burdens of NCDs, over 90\% reported mortality data, whereas only 10 had population-based data and only 7 reported cause-specific mortality. ${ }^{26}$ Furthermore, there was little information on data quality, frequency of data collection, and standardization of methods.

The European Cancer Health Indicator Project (EUROCHIP) represents one attempt to improve NCD surveillance. While specifically concerned with cancer, EUROCHIP has 41 indicators across five broad categories with important overlaps with other NCDs, including behavioral, environmental and occupational risk as well as social, macroeconomic and demographic indicators. ${ }^{39}$ Since these indicators were published in 2003, all EU member states have made significant progress in making this information available to researchers and the public.

\section{Enabling Capacity: Human and Technological Resources}

"In simple terms, the public health infrastructure consists of the resources and relationships necessary to carry out the core functions and essential services of public health."

Turnock, BJ. Public health: What it is and how it works. 4th ed. ${ }^{40}$

In this commentary, we consider public health infrastructure in the interconnected domains of human resources and technological infrastructure. 


\section{Human Resources for Public Health}

"At the heart of all successful public health activities in government agencies as well as in the private and voluntary sectors are public health workers. They focus on populations and communities, and, in their efforts to ensure quality and accessibility of health services, they apply their knowledge of epidemiology and biostatistics and their ability to build coalitions and support systemic change."

Gebbie, KM. The public health workforce: Key to public health infrastructure. ${ }^{41}$

The global SARS crisis of 2002 highlighted the importance of public health human resources in addressing a major public health crisis. Countries such as Canada responded to widespread criticism by carrying out a formal analysis of the public health response to $\mathrm{SARS}^{42}$ and subsequently developing a vision and framework for human resource planning. The ultimate goal was to build a knowledgeable workforce with the skills and competencies to address evolving public health needs; for example, the rising incidence of NCDs in an aging population. ${ }^{43}$

\section{Why are human resources for public health important?}

In a sector as labour-intensive as health, a nation's public health workforce is the "backbone of the public health infrastructure, critical to the success of public health programs." ${ }^{44}$ This multidisciplinary workforce, trained for public health, provides essential public health services and includes nurses, physicians, nutritionists, epidemiologists, laboratory and inspection personnel and health promotion specialists employed in the public and private sectors and NGOs. ${ }^{44}$ Barriers to effective public health functioning include fragmentation of the health system, poor training and capacity, insufficient resources, low pay, and low morale. ${ }^{36}$ The expected increase in the burden of NCDs escalates the need for public health personnel focused on this area, ${ }^{43}$ which was also identified as a priority at the 2011 UN Highlevel meeting on NCDs. ${ }^{12}$

\section{Attributes of effective human resources for public health}

Human resources planning. HR planning is essential for developing and maintaining a responsive and competent public health workforce; it requires an understanding of the state of the workforce and training needs for competencies for future NCD-prevention. The WHO recommends that countries conduct public health skills audits to identify potential deficits in health human resources and required competencies ${ }^{36}$ However, this may be 
difficult because of the limitations in monitoring the size and composition of the workforce ${ }^{44,45}$ and the limited evidence that assesses the impact on health outcomes from public health human resource inputs. Such evidence could be used to forecast need and support the call for more investment in the health workforce. ${ }^{44}$ For instance, a recent U.S. study showed that increases in staffing expenditure at the local health department level were significantly associated with a decrease in mortality due to cardiovascular disease (associations were not observed for cancer deaths or the prevalence of smoking and obesity). ${ }^{46}$

Producing, training, and retaining skilled workers. Highly trained workers from many disciplines are required to address the complexity of NCD prevention. Workforce development, including training and technical assistance, is associated with improved organizational performance. ${ }^{19}$ Educational programs should be aligned with the needs of the public health sector, ${ }^{36,47}$ with best practices and innovative models identified and shared. ${ }^{36,43,47}$ Other recommendations include providing adequate compensation and incentives to attract and retain skilled workers for underserviced areas ${ }^{13}$ and permitting flexible work arrangements. ${ }^{45}$

Although there is little research specific to public health workers ${ }^{45}$ the globalization of the health workforce as a whole (medical migration) has increased the research focus on health worker satisfaction, particularly in low income settings, where the deficit in health workers-including the loss of resources associated with training health workers who later migrate-is most pronounced. ${ }^{48}$ The WHO's Global Code of Practice on the International Recruitment of Health Personnel includes recommendations for professional training, worker retention and ethical recruitment for both source and destination countries. ${ }^{49}$

Focus on competencies. Organizations such as WHO and ASPHER (the Association of Schools of Public Health in the European Region) urge governments to identify and invest in building public health core competencies, that is, the essential, cross-disciplinary knowledge, skills and attitudes required to address NCDs. ${ }^{13,36,43,50,51}$ Competencies for NCD prevention include leading strategically; building partnerships; influencing policies and systems change; managing people, programs and resources; designing and evaluating programs; and using evidence-based processes ${ }^{52,53}$ All nations, including developed ones, face the issue of competency (see Box 3). 


\section{Box 3}

A 2012 systematic review reported that $80 \%$ of the approximately 500,000 public health professionals in the U.S. lack the formal education or field training to do their jobs effectively. ${ }^{45}$

There is also a gap between the structure and programs offered in traditional schools of public health and public health competencies. ${ }^{54}$ Increasing workforce capacity through standards such as certification or accreditation is one possible approach, but there is limited evidence to support this. ${ }^{19,44}$ Reorienting public health jobs along competency domains, rather than health disciplines, may be a more effective solution. ${ }^{43}$

\section{Enabling Capacity: Technological Resources}

"If public health's effectiveness and profile are to grow, practitioners and researchers will need reliable, timely information with which to make information-driven decisions, better ways to communicate, and improved tools to analyze and present new knowledge."

Friede, A. Public health informatics: How information-age technology can strengthen public health. ${ }^{55}$

Why are technological resources important?

Technological innovations can enhance surveillance and population health assessment systems and also support data capture for performance monitoring, accountability, research and evaluation. Technology can also extend the reach of the public health workforce; for instance, informationcommunication technologies are being used more often as cost-effective vehicles for health promotion interventions, such as health education and social marketing, ${ }^{54}$ and digital tools are replacing bulky printed volumes used to guide practice, for example in the American Health People 2020

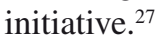

\section{Attributes of effective technological resources}

Creating and sharing information. Technological resources are required to monitor progress towards achieving NCD targets. Technology can facilitate the exchange of data, evidence on interventions and resources between practitioners and researchers, while enhancing partnerships. It is particularly important to increase capacity in settings where resources are scarce. ${ }^{50} \mathrm{At}$ national and other levels, the availability of population-based surveys, large administrative datasets, and robust computing capacity allow for complex 
and novel analyses on the burden of disease and the relationships between exposures and outcomes over time..$^{56,57}$

The participatory nature of the internet enables the passive collection of user data and the public participation in crowd-sourced health research. ${ }^{58}$ User information, such as gender and age, is central to the design of effective, targeted internet-based interventions (see below). ${ }^{59}$ Similarly, analysis of mobile phone GPS data and Twitter activity can complement traditional data collection methods. Work in this area must be transparent, carefully balancing the expectations of privacy and public health good; disregarding this need may undermine public trust, data quality, and ultimately, the effectiveness of the intervention.

Health promotion interventions delivered through technology. New, widely available technologies enable a broad reach and the rapid roll-out of tailored health messages. ${ }^{60}$ Interactive internet and mobile phone applications can be used to support individual goal setting and behavior change, enabling users to share experiences with each other or with health professionals. Emerging evidence has demonstrated the (variable) effectiveness of internet-based interventions on a wide range of health behaviors and clinical outcomes, such as weight loss, smoking cessation and problem drinking. ${ }^{58}$ On the other hand, such sites can also serve as social networks that validate behavioral diseases, such as eating disorders, among others.

The impact of new technologies on health equity has been a source of debate, with some arguing that differential access to technology may exacerbate health inequalities across the "digital divide," ${ }^{61}$ and others suggesting that the widespread availability of some devices (such as mobile phones) may actually improve access to interventions. ${ }^{59}$ There are no definitive answers at the present; however, further research may shed light on how to enhance the reach and effectiveness of these interventions. ${ }^{58}$

\section{Enabling Capacity: Research and Evaluation}

"Population health intervention research involves the use of scientific methods to produce knowledge about policy and program interventions that operate within or outside of the health sector and have the potential to impact health at the population level."

Canadian Institutes of Health Research. Population Health Intervention Research Initiative for Canada ("PHIRIC") Workshop Report. As cited in Hawe and Potvin. ${ }^{62}$ 
Why are research and evaluation important?

The WHO global action plan ${ }^{13}$ underlines the need for improved national research capacity to support NCD prevention and control. ${ }^{13}$ Access to timely and reliable research and evaluation allows decision-makers to judge the relevance and likely impact of interventions and consider alternatives. ${ }^{63}$ Research should also be contextual and include perspectives from outside the health sector. ${ }^{64}$ The limited capacity of LMICs to develop contextually relevant evidence may be a significant barrier towards achieving NCDs targets (see Box 4).

\section{Box 4}

A recent WHO survey found that while $75 \%$ of countries have scientific research agencies, fewer $(61 \%)$ have capacity for policy research. This deficiency is especially marked in lowand middle-income countries (LMICs), where just over half (57\%) have policy research capacity compared to $75 \%$ of high-income countries. ${ }^{12}$

\section{Attributes of effective research and evaluation}

Research relevant to NCD prevention and control. Translating research into improved health outcomes requires a shift to action-oriented intervention research that addresses policies and programs. ${ }^{65}$ Evaluation must be rigorous, using appropriate study designs to assess reach, adoption, implementation, maintenance, costs and health outcomes. ${ }^{61,63,66}$ Both intended and unintended effects of population health interventions should be considered, as well as the impact of policies and programs from nonhealth sectors on exposure to risk factors and health outcomes. ${ }^{61}$ The impacts of universal interventions across sub-populations must be examined, particularly in groups where the social determinants of health pose a greater risk of NCDs.

Several areas of research can assist in answering questions relevant to the prevention and control of NCDs; for example, population health intervention research, ${ }^{61}$ public health systems and service research, ${ }^{67,68}$ analysis of social networks, ${ }^{69,70}$ studies of the interplay between genetic, social, behavioral and environmental exposures across the life course, ${ }^{71}$ and health equity-focused research.

\section{Evaluate local applicability}

Decision-making at the local and regional levels must consider contextual evidence relevant to the population of concern. Without careful consideration 
of local feasibility, acceptability and utility, an intervention that is adapted from a specific population may fail when applied in a different setting, even when the intervention is supported by strong evidence in other populations. ${ }^{61,65,72}$ Evaluation, including practical analyses that ask, "What works for whom in what circumstances and in what respects, and how?" is essential to understanding, refining and improving NCD program and policy interventions. ${ }^{73,74}$

\section{Enabling Capacity: Knowledge Mobilization Infrastructures}

Knowledge mobilization "encompasses methods of knowledge transfer, translation and exchange and extends them to include the co-production

of knowledge. Knowledge mobilization turns research into action."

ResearchImpact. ResearchImpact FAQs. ${ }^{75}$

Enabling individual capacity refers to increasing knowledge, skills and abilities in core public health and NCD prevention competencies. Enabling organizational capacity refers to changing environmental and cultural factors to remove systemic barriers and facilitate good organizational performance. Both are essential to making a positive impact on NCD prevention.

Why is knowledge mobilization important?

Policy is often neither evidence-based nor evidence-informed. Research evidence is often only one factor among many that decision-makers consider while developing policies. The extent to which evidence is used to make public health decisions is difficult to quantify but is likely to be low. ${ }^{71,76}$ Several studies have identified individual and organizational barriers to the translation of knowledge into evidence-based decisionmaking. These barriers included mistrust and communication gaps between researchers and decision-makers, external and internal constraints, barriers in access to relevant information, incompatible timeframes, and perceived lack of organizational support for evidence-based decision making. ${ }^{71,77,78}$

Knowledge mobilization can empower society and improve accountability. Knowledge mobilization is essential to support implementation of public health policies, regulations and services that are responsive to the needs of a population, ${ }^{11,14}$ and it should occur continuously between decisionmakers, the public health workforce, researchers, and civil society. ${ }^{14,79}$

International cooperation is strengthened by exchanging best practices in health promotion, legislation and regulation, training, and health care infrastructure development. ${ }^{12}$ This also includes best practices on effective whole-of-government approaches ${ }^{8,11,14,15}$ and the translation of evidence on "best buys" into policies and programs that can be implemented. ${ }^{33}$ 
Enhancing the capacity to collaborate among government sectors can increase the effectiveness of multi-sectoral action; for example, by creating opportunities for engagement, exploring shared values, and building knowledge and practice networks. ${ }^{33}$

Enhancing "the interface between scientific evidence and policymaking" $" 80$ may make research more relevant to policymakers and decrease the time from discovery to translation and, ultimately, policy and practice. ${ }^{13,81}$ This collaboration could be facilitated by individual capacity building (e.g., increasing decision-makers' ability to understand evidence), cultural exchange and improved communication tools and techniques. ${ }^{71,76,82}$

However, the most effective knowledge brokering is bi-directional, and research will only have an increased impact on policy when it responds to policymakers' needs. In the recently concluded BRIDGE project in Europe ${ }^{83}$ three factors were found to consistently influence the translation of research knowledge to the policy sphere: (1) formal and informal linkages between researchers and policymakers; (2) alignment between research findings and the beliefs, values, interests or political goals of elected officials; and (3) timely availability of information. Innovative knowledge-brokering mechanisms included the celebration of policy dialogues and workshops, and the preparation of specific policy briefs in accessible language that analyze the pros and cons of different options. ${ }^{84}$

\section{Attributes of effective knowledge mobilization actions}

Increased community capacity. Building capacity for community-based action is essential for NCD prevention and control. ${ }^{47}$ Integrated solutions need a range of civil society partners, such as social and religious organizations, community groups and primary care providers, to strengthen health systems and response capacity. ${ }^{85}$ At the national level, capacity building among NCD-related NGOs can establish a social movement and increase a community-based organization's ability to reach their full potential as partners. ${ }^{33}$ As Brownson states, "An effective coalition has the power to influence chronic disease control policies and community-level actions far beyond the influence of any single member." ${ }^{\text {81 }}$

Capacity building infrastructure. Finally, these facets of capacity building cannot be enabled without an investment in scientific, educational and technical support infrastructures. Canada in particular has recently established specialized public health agencies and centres of excellence at both national and provincial levels. These enabling knowledge organizations were created largely in response to the SARS crisis of 2002-03, and some have a health promotion and NCD prevention mandate. ${ }^{86}$ 
These institutions also provide important training opportunities for students in a variety of academic backgrounds. Given the central coordinating function and broad mandate, much of the work is conducted in partnership with other stakeholders, including government. ${ }^{85}$ Also resulting from deficiencies in the SARS episode was the development of a number of Masters of public health training programs in universities across Canada. ${ }^{42}$

\section{Enabling Capacity: Financial Transfers}

"Financing is concerned with the mobilization, accumulation and allocation of money to meet the population's health needs, individually and collectively. The purpose of health financing is to make funding available, as well as to set the right financial incentives for providers, so as to ensure that all individuals have access to effective public health and personal health care."

World Health Organization. Strengthening public health capacities and services in Europe: A framework for action - Interim draft. ${ }^{36}$

Why are financial transfers important?

Funding to prevent NCDs has historically been low compared to the impact of these conditions. ${ }^{36}$ It may even be argued that the lack of investment has contributed to the strong trajectory of the epidemic, especially among developed countries where the disease burden long ago shifted from infectious to chronic diseases. In the world's poorest countries, the lack of funding, coordination of funds, and priority setting has been a serious detriment in meeting the millennium development goals and the rising pandemic of NCDs. ${ }^{87}$

Financial transfers include the public funding of national or local health departments for NCD prevention and control, grants for research, and funds for community agencies or NGOs to implement population NCD interventions. Interventions that address NCDs should have flexible yet sustained funding, nimble accounting mechanisms, and adequate supporting infrastructure for financial management. Importantly, financial transfers have the potential to impact all other capacities discussed in this commentary.

NCD s contribute significantly to economic losses. NCDs and the related risk factors contribute to significant losses in national productivity, and can impoverish individuals, families and communities. ${ }^{7,12,38}$ The burden of NCDs in low- and middle-income countries contributes to poverty and is a major barrier to economic development. ${ }^{88}$ NCDs cause significant productivity loss: for every $10 \%$ rise in mortality related to NCDs, the estimated reduction 
in yearly economic growth is $0.5 \%{ }^{89}$ (see Box 5), yet modest investments in population-level interventions could save millions of lives.

\section{Box 5}

At the present levels of NCD prevalence and intervention effort, economic losses in LMICs are projected to exceed US\$7 trillion, between 2011 and 2025. Of these economic losses, the greatest contributions come from cardiovascular diseases $(51 \%)$, respiratory diseases $(22 \%)$, cancer $(21 \%)$ and diabetes $(6 \%) .{ }^{90,91}$

\section{Attributes of effective financial transfers}

Adequate and sustained government funding for NCDs. Financial transfers must be adequate and sustained to address the burden of illness due to NCDs. WHO recommends that countries "prioritize and increase, as needed, budgetary allocations for prevention and control of NCDs..." as well as tracking resources for research. ${ }^{13}$ This recommendation is supported by other global strategies and action plans on NCDs. ${ }^{8,11,12,36,84,92}$

Prioritization of "best buys." The most cost-effective interventions for reducing exposure to risk factors and burden of illness should be prioritized for implementation. Several "best buys" have been identified by WHO to address tobacco use, harmful use of alcohol, unhealthy diet and physical inactivity, CVD and diabetes, and cancer. ${ }^{90}$ The projected cost of implementing these best buys across all LMICs between 2011 and 2015 would average US $\$ 11.4$ billion annually (US\$1.00-3.00 per capita or $1-4 \%$ of overall health spending). ${ }^{90}$ Implementing priority interventions could reduce overall global mortality by $2 \%$ annually at a cost of less than US $\$ 1000$ per disability-adjusted life year. ${ }^{93}$

Multiple sources of stable funding. Funding for NCD interventions should be sustainable, flexible, predictable, and available through multiple sources. Funding should be available for overall NCD prevention, not just earmarked for specific diseases. ${ }^{79}$ The UN suggests that countries explore sources of adequate and sustained funding through domestic, bilateral, regional and multilateral channels; governments should also consider developing and implementing voluntary, cost-effective, innovative approaches for long-term financing of NCD prevention. ${ }^{12-14,38}$ 


\section{Enabling Capacity: Effective Policy, Program and Communication Interventions}

Healthy public policies are "public policies, outside the formal health sector, that have an impact on health, such as education, transportation, and fiscal policies."

Farad, P. Evidence and healthy public policy: Insights from health and political sciences..$^{94}$

Health communication is "The study and use of communication strategies to inform and influence individual decisions that enhance health."

Centers for Disease Control and Prevention. Health communication basics. $^{95}$

Attributes of effective policy, program and communication interventions

Systematic framework for policy development. The Pan-American Health Organization identifies the need for a systematic, public policy framework as the first step in addressing NCDs. This framework should define priority policies, establish mechanisms for assessment and evaluation, engage all sectors of society and facilitate the sharing of technical knowledge between countries. ${ }^{47}$

Alignment of policies across health and non-health sectors. Effective national strategies to address NCDs require integrated policies governing health and non-health sectors, including agriculture, industry, transport, and trade $;{ }^{25}$ however, this is not always the case. In agriculture, for example, the government may fund programs to fight obesity while subsidizing crops such as corn, which is processed into high-fructose corn syrup, a sweetener in mass-produced foods. ${ }^{96}$ The Adelaide Statement (2010) calls for a "joined-up" government approach to healthy public policies. It describes the health in all policies approach, including health impact assessment tools and instruments, drivers for change and a new role for the health sector. ${ }^{97}$

Addressing the social determinants of health. WHO recognizes the need to address the social determinants of health as part of the strategy to address NCDs, building on the findings of the WHO Commission on Social Determinants of Health. ${ }^{13,98}$ Inequities in protection from risk factors and access to health care can lead to inequalities in the occurrence and outcome of NCDs. ${ }^{13}$ Unless public policies (including financial policies) address these underlying determinants, health equity is unlikely to be achieved.

Systematic approach to health communication. Communication is a fundamental component of public health..$^{99}$ It is a key functional capacity 
recognized by $\mathrm{CDPAC},{ }^{16} \mathrm{CDC}^{95}$ and the $\mathrm{UN} .{ }^{38}$ Health communication is most effective when informed by both evidence and practice. A systematic approach may also be adopted that includes scoping the problem, setting objectives, identifying targets and stakeholders, and testing messaging. Finally, processes and outcomes should be evaluated to determine effectiveness and to further refine strategy, messages and tactics. ${ }^{94}$

Ecological approach to health communication. An ecological approach to health communication recognizes that health is affected by social, political, environmental and behavioral factors. Thus, health communication strategies must address social, physical and environmental risk factors, targeting individuals, groups and communities. ${ }^{98}$ Specific interventions, such as a public education campaign, need to be implemented with sufficient reach and intensity, adapted to the local context, and sustained over time.

\section{CONCLUSION}

"[M]ore than a goal, [public health] must become a collective value, sustaining our society's quest for a better life for all human beings."

Halpin H, Morales-Suárez-Varela M, Martín-Moreno JM. Chronic disease prevention and the new public health. ${ }^{24}$

Values drive policy and action-one must believe in something to achieve change. The value of health as a basic human right and public good drives NCD prevention. However, in the absence of effective action, the burden of NCDs will only experience rapid growth, threatening the sustainability of social and health systems.

Leadership is perhaps the most critical and rate-limiting enabling capacity in the prevention of NCDs. Strong leadership can inspire, set a vision, create strategy, support implementation, and manage accountability. However, at a time when public sector leadership is most desperately needed, the political will to lead change has often faltered, leading to shortfalls in key enabling capacities. It is time for those in leadership positions to put the public's health at the top of their agendas and to adopt a participatory approach that integrates science, practice and equitable social policy. Knowledge mobilization must take centre stage, as public policies that are driven by ideology and competing interests may ignore scientific evidence and expert recommendations.

Building public sector capacity for NCD prevention enables the delivery of contextually appropriate, relevant and effective policy, program and health communication interventions. NCD prevention must also address 
the impact of the multiple interacting social determinants of health, in order to reduce health inequity and improve the public's health. Importantly, public sector leadership capacity is essential to enabling multi-sectoral partnerships that can take action on risk factors and determinants to create real change. Public sector leaders need to sstrengthen networking approaches, involving local and regional governments, international organizations and others to develop integrated and creative partnerships addressing health equity and NCDs. The public sector cannot lead without strong political commitment to health as a basic human right coupled with a commitment to intervene to protect the population's health.

Acknowledgements: We would like to thank Chris Mercer, who assisted in the preparation of early drafts, and Dr. Vivek Goel and our external reviewers for their thoughtful review and helpful suggestions. We also gratefully acknowledge Meggan Harris' support during the drafting and editing of the manuscript.

Conflicts of Interest: None declared.

\section{REFERENCES}

1. Lozano R, Naghavi M, Foreman K, Lim S, Shibuya K, Aboyans V, et al. Global and regional mortality from 235 causes of death for 20 age groups in 1990 and 2010: a systematic analysis for the Global Burden of Disease Study 2010. Lancet. 2012;380:2095-128.

2. Lim SS, Vos T, Flaxman AD, Danaei G, Shibuya K, Adair-Rohani H, et al. A comparative risk assessment of burden of disease and injury attributable to 67 risk factors and risk factor clusters in 21 regions, 1990-2010: a systematic analysis for the Global Burden of Disease Study 2010. Lancet. 2012;380:222460 .

3. Bloom DE, Cafiero ET, Jané-Llopis E, Abrahams-Gessel S, Bloom LR, Fathima $\mathrm{S}$, et al. The global economic burden of noncommunicable diseases. Geneva (CH): World Economic Forum; 2011. Available from URL: http://www3. weforum.org/docs/WEF_Harvard_HE_GlobalEconomicBurdenNon CommunicableDiseases_2011.pdf (Accessed 13 June 2014).

4. Figueras J, McKee M, Lessof S, Duran A, Menabde N. Health systems, health and wealth: assessing the case for investing in health systems. Geneva $(\mathrm{CH})$ : World Health Organization; 2008. Available from URL: http://www.euro.who. int/_data/assets/pdf_file/0017/91430/E93699.pdf (Accessed 13 June 2014).

5. The Ottawa Charter for Health Promotion: first international conference on health promotion, Ottawa, 21 November 1986. Available from URL: http:// www.who.int/healthpromotion/conferences/previous/ottawa/en/ (Accessed 13 June 2014). 
6. World Health Organization, 53rd Assembly. Global strategy for the prevention and control of noncommunicable diseases: report by the Director-General. Geneva (CH): World Health Organization; 2000. Available from URL: http:// apps.who.int/gb/archive/pdf_files/WHA53/ea14.pdf (Accessed 13 June 2014).

7. World Health Organization. 2008-2013 action plan for the global strategy for the prevention and control of noncommunicable diseases. Geneva $(\mathrm{CH})$ : World Health Organization; 2008. Available from URL: http://whqlibdoc.who.int/ publications/2009/9789241597418_eng.pdf (Accessed 13 June 2014).

8. World Health Organization. WHO framework convention on tobacco control. Geneva (CH): World Health Organization; 2003. Available from URL: http:// whqlibdoc.who.int/publications/2003/9241591013.pdf (Accessed 13 June 2014).

9. World Health Organization. Global strategy on diet, physical activity and health. Geneva (CH): World Health Organization; 2004. Available from URL: http:// www.who.int/dietphysicalactivity/strategy/eb11344/strategy_english_web. pdf (Accessed 13 June 2014).

10. World Health Organization Regional Office for Europe. The first action plan for food and nutrition policy: WHO European Region 2000-2005. Copenhagen (DK): World Health Organization; 2001. Available from URL: http://www. euro.who.int/_data/assets/pdf_file/0013/120244/E72199.pdf (Accessed 13 June 2014).

11. World Health Organization. Global strategy to reduce the harmful use of alcohol. Geneva $(\mathrm{CH})$ : World Health Organization; 2010. Available from URL: http://www.who.int/substance_abuse/msbalcstragegy.pdf (Accessed 13 June 2014).

12. World Health Organization. UN high-level meeting on NCDs: summary report of the discussions at the round tables. Geneva $(\mathrm{CH})$ : World Health Organization; 2012. Available from URL: http://www.who.int/nmh/events/ moscow_ncds_2011/round_tables_summary.pdf (Accessed 13 June 2014).

13. World Health Organization. Global action plan for the prevention and control of noncommunicable diseases 2013-2020. Geneva (CH): World Health Organization; 2013. Available from URL: http://www.who.int/iris/ bitstream/10665/94384/1/9789241506236_eng.pdf (Accessed 13 June 2014).

14. World Health Organization. Revised WHO discussion paper: a comprehensive global monitoring framework, including indicators, and a set of voluntary global targets for the prevention and control of noncommunicable diseases. Geneva (CH): World Health Organization; 2012. Available from URL: http://www.who. int/nmh/events/2012/discussion_paper3.pdf (Accessed 13 June 2014).

15. World Health Organization, 66th Assembly. Follow-up to the political declaration of the High-Level Meeting of the General Assembly on the Prevention and Control of Non-communicable Diseases. Geneva $(\mathrm{CH})$ : World Health Organization; 2013. Available from URL: http://ncdalliance. org/sites/default/files/rfiles/Final\%200R\%20with\%20GAP_A66_R10-en. pdf Accessed 13 June 2014). 
16. Riley B, Garcia J. Primary prevention of chronic diseases in Canada: a framework for action. Ottawa (ON): Chronic Disease Prevention Alliance of Canada; 2008. Available from URL: http://www.cdpac.ca/media.php?mid= 451 (Accessed 13 June 2014).

17. Koh HK. Leadership in public health. J Cancer Educ. 2009;24:S11-8.

18. Day M, Shickle D, Smith K, Zakariasen K, Oliver T, Moskol J. Time for heroes: public health leadership in the 21st century. Lancet. 2012;380:1205-6.

19. Brownson RC, Allen P, Duggan K, Stamatakis KA, Erwin PC. Fostering moreeffective public health by identifying administrative evidence-based practices: a review of the literature. Am J Prev Med. 2012;43:309-19.

20. Yuki G. Effective leadership behavior: what we know and what questions need more attention. Acad Manag Perspect. 2012;26:66-85.

21. United Nations Economic and Social Council, CESCR Committee on Economic, Social and Cultural Rights, 22nd Session. The right to the highest attainable standard of health (E/C.12/2000/4). New York (NY): United Nations; 2000. Available from URL: http://www.unhchr.ch/tbs/doc.nsf/ (symbol)/E.C.12.2000.4.En (Accessed 18 February 2014).

22. United Nations General Assembly. The universal declaration of human rights. New York (NY): United Nations; 1948. Available from URL: http://www. un.org/en/documents/udhr/ (Accessed 13 June 2014).

23. United Nations General Assembly. International covenant on economic, social and cultural rights. New York (NY): United Nations; 1966. Available from URL: http://www.ohchr.org/EN/ProfessionalInterest/Pages/CESCR.aspx (Accessed 13 June 2014).

24. Halpin H, Morales-Suárez-Varela M, Martín-Moreno JM. Chronic disease and the new public health. Public Health Rev. 2010;32:120-54.

25. Beaglehole R, Bonita R, Horton R, Adams C, Alleyne G, Asaria P, et al. Priority actions for the non-communicable disease crisis. Lancet. 2011;377:1438-47.

26. Alwan A, Maclean DR, Riley LM, d'Espaignet ET, Mathers CD, Stevens GA, et al. Monitoring and surveillance of chronic non-communicable diseases: Progress and capacity in high-burden countries. Lancet. 2010;376:1861-8.

27. Fielding JE, Kumanyika S, Manderscheid RW. A perspective on the development of the healthy people 2020 framework for improving U.S. population health. Public Health Rev. 2014;35: epub ahead of print.

28. Bill \& Melinda Gates Foundation. How we work. Seattle (WA): Bill \& Melinda Gates Foundation; 2013. Available from URL: http://www.gatesfoundation. org/How-We-Work (Accessed 13 June 2014).

29. Cancer Research UK. Our story. London (UK): Cancers Research UK; 2013. Available from URL: http://www.cancerresearchuk.org/about-us/who-weare/our-story/ (Accessed 19 April 2013).

30. Fox T, Ward H, Howard B. Public sector roles in strengthening corporate social responsibility: a baseline study. Washington (DC): The World Bank; 2002. Available from URL: http://pubs.iied.org/pdfs/16017IIED.pdf (Accessed 13 June 2014). 
31. text4baby. Available from URL: https://text4baby.org/ (Accessed 13 June 2014).

32. Whittaker R, Matoff-Stepp S, Meehan J, Kendrick J, Jordan E, Stange P, et al. Text4baby: development and implementation of a national text messaging health information service. Am J Public Health. 2012;102:2207-13.

33. United Nations General Assembly, 67th Session. Note by the Secretary-General transmitting the report of the Director-General of the World Health Organization on options for strengthening and facilitating multisectoral action for the prevention and control of non-communicable diseases through effective partnership (A/67/373). New York (NY): United Nations; 2012. Available from URL: http://www.who.int/nmh/events/2012/20121128.pdf? ua=1 (Accessed 13 June 2014).

34. World Health Organization. Assessing national capacity for the prevention and control of noncommunicable diseases: report of the 2010 global survey. Geneva (CH): World Health Organization; 2012. Available from URL: http:// www.who.int/cancer/publications/national_capacity_prevention_ncds.pdf (Accessed 13 June 2014).

35. German RR, Lee LM, Horan JM, Milstein RL, Pertowski CA, Waller MN, et al. Updated guidelines for evaluating public health surveillance systems: recommendations from the guidelines working group. MMWR Recomm Rep. 2001;50:1,35.

36. World Health Organization. Strengthening public health capacities and services in Europe: a framework for action - interim draft. Geneva $(\mathrm{CH})$ : World Health Organization; 2011. Available from URL: http://www.euro.who.int/_data/ assets/pdf_file/0011/134300/09E_StrengtheningPublicHealthFramework_ 110452_eng.pdf (Accessed 13 June 2014).

37. Hall HI, Correa A, Yoon PW, Braden CR, Centers for Disease Control and Prevention. Lexicon, definitions, and conceptual framework for public health surveillance. MMWR Surveill Summ. 2012;61 Suppl:10-4. Available from: http://www.cdc.gov/mmwr/preview/mmwrhtml/su6103a3.htm (Accessed 13 June 2014).

38. United Nations General Assembly, 66th Session. Political declaration of the high-level meeting of the General Assembly on the prevention and control of non-communicable diseases (A/RES/66/2). New York (NY): United Nations; 2011. Available from URL: http://www.who.int/nmh/events/un_ncd_summit 2011/political_declaration_en.pdf (Accessed 13 June 2014).

39. EUROHIP: European cancer health indicator project. Available from URL: http://www.tumori.net/eurochip/ (Accessed 13 June 2014).

40. Turnock BJ. Public health: what it is and how it works. 4th ed. Sudbury (MA): Jones \& Bartlett Learning; 2008.

41. Gebbie KM. The public health workforce: key to public health infrastructure. Am J Public Health. 1999;89:660-1.

42. Masse R, Moloughney B. New era for schools and programs of public health in Canada. Public Health Rev. 2011;33:277-88. Available from URL: http:// www.publichealthreviews.eu/upload/pdf_files/9/ATT00095.pdf (Accessed 13 June 2014). 
43. Joint Task Group on Public Health Human Resources. Building the public health workforce for the 21st century: a pan-Canadian framework for public health human resources planning. Ottawa $(\mathrm{ON})$ : Her Majesty the Queen in Right of Canada; 2005. Available from URL: http://www.ciphi.ca/files/ documents/cpc/ccworkforce.pdf (Accessed 13 June 2014).

44. Beck AJ, Boulton ML. Building an effective workforce: a systematic review of public health workforce literature. Am J Prev Med. 2012;42:S6-16.

45. Hilliard TM, Boulton ML. Public health workforce research in review: a 25-year retrospective. Am J Prev Med. 2012;42:S17-28.

46. Erwin PC, Greene SB, Mays GP, Ricketts TC, Davis MV. The association of changes in local health department resources with changes in state-level health outcomes. Am J Public Health. 2011;101:609-15.

47. Pan American Health Organization. Regional strategy and plan of action on an integrated approach to the prevention and control of chronic diseases. Washington (DC): Pan American Health Organization; 2007. Available from URL: http://www1.paho.org/english/ad/dpc/nc/reg-strat-cncds.pdf (Accessed 13 June 2014).

48. Willis-Shattuck M, Bidwell P, Thomas S, Wyness L, Blaauw D, Ditlopo P. Motivation and retention of health workers in developing countries: a systematic review. BMC Health Serv Res. 2008;8:247,6963-8-247. Available from: http:// www.biomedcentral.com/1472-6963/8/247(Accessed 13 June 2014).

49. World Health Organization, 63rd Assembly. The WHO global code of practice on the international recruitment of personnel (WHA63.16). Geneva $(\mathrm{CH})$ : World Health Organization; 2012. Available from URL: http://www.who.int/ hrh/migration/code/code_en.pdf (Accessed 13 June 2014).

50. Public Health Agency of Canada. Core competencies for public health in Canada: release 1.0. Ottawa $(\mathrm{ON})$ : Her Majesty the Queen in Right of Canada; 2007. Available from URL: http://publications.gc.ca/collections/ collection_2008/phac-aspc/HP5-51-2008E.pdf (Accessed 13 June 2014).

51. Birt C, Foldspang A. The developing role of systems of competences in public health education and practice. Public Health Rev. 2011;33:134-47. Available from URL: http://www.publichealthreviews.eu/upload/pdf_files/9/Birt_update. pdf (Accessed 13 June 2014).

52. Brownson RC, Ballew P, Kittur ND, Elliott MB, Haire-Joshu D, Krebill H, et al. Developing competencies for training practitioners in evidence-based cancer control. J Cancer Educ. 2009;24:186-93. Available from URL: http://www. ncbi.nlm.nih.gov/pmc/articles/PMC3877239/ (Accessed 13 June 2014).

53. Slonim A, Wheeler FC, Quinlan KM, Smith SM. Designing competencies for chronic disease practice. Prev Chronic Dis. 2010;7:A44. Available from URL: http://www.cdc.gov/pcd/issues/2010/Mar/08_0114.htm (Accessed 13 June 2014).

54. Beaglehole R, Dal Poz MR. Public health workforce: challenges and policy issues. Hum Resour Health. 2003;1:4. Available from URL: http://www. human-resources-health.com/content/1/1/4 (Accessed 13 June 2014). 
55. Friede A, Blum HL, McDonald M. Public health informatics: How informationage technology can strengthen public health. Annu Rev Public Health. 1995;16:239-52.

56. Ratnasingham S, Cairney J, Rehm J, Manson H, Kurdyak PA. Opening eyes, opening minds: the Ontario burden of mental illness and addictions report. Toronto (ON): Institute for Clinical Evaluative Sciences and Public Health Ontario; 2012. Available from URL: http://www.publichealthontario.ca/en/ eRepository/Opening_Eyes_Report_En_2012.pdf (Accessed 13 June 2014).

57. World Health Organization. The global burden of disease: 2004 update. Geneva (CH): World Health Organization; 2004. Available from URL: http://www. who.int/healthinfo/global_burden_disease/GBD_report_2004update_full. pdf (Accessed 13 June 2014).

58. Swan M. Crowdsourced health research studies: an important emerging complement to clinical trials in the public health research ecosystem. J Med Internet Res. 2012;14:e46. Available from URL: http://www.ncbi.nlm.nih. gov/pmc/articles/PMC3376509/ (Accessed 13 June 2014).

59. Bennett GG, Glasgow RE. The delivery of public health interventions via the internet: actualizing their potential. Annu Rev Public Health. 2009;30:27392.

60. Martín-Moreno JM, Apfel F, Sanchez JL, Galea G, Jakab Z. The social nature of chronic noncommunicable diseases and how to tackle them through communication technology, training, and outreach. J Health Commun. 2011;16 Suppl 2:94-106.

61. Murray E. Web-based interventions for behavior change and self-management: Potential, pitfalls and progress. Medicine 2.0. 2012;1(1/e3):1.

62. Hawe P, Potvin L. What is population health intervention research? Can J Public Health. 2009;100:Suppl I8-14. Available from URL: http://journal. cpha.ca/index.php/cjph/article/view/1748/1933 (Accessed 13 June 2014).

63. Treasury Board of Canada Secretariat. Policy on evaluation. Ottawa (ON): Her Majesty the Queen in Right of Canada; 2012. Available from URL: http:// www.tbs-sct.gc.ca/pol/doc-eng.aspx?section=text\&id=15024 (Accessed 13 June 2014).

64. Glasgow RE, Vogt TM, Boles SM. Evaluating the public health impact of health promotion interventions: the RE-AIM framework. Am J Public Health. 1999;89:1322-7. Available from URL: http://www.ncbi.nlm.nih.gov/pmc/ articles/PMC1508772/ (Accessed 13 June 2014).

65. Population Health Intervention Research Initiative for Canada. Population Health Intervention Research Initiative for Canada ("PHIRIC") workshop report. Ottawa (ON): Canadian Institute for Health Information; 2007. Available from URL: http://www.cihi.ca/CIHI-ext-portal/pdf/internet/ BANFF_WORKSHOP_PROCEEDINGS_EN (Accessed 18 February 2014). 
66. Puddy RW, Wilkins N. Understanding evidence part 1: best available research evidence. A guide to the continuum of evidence of effectiveness. Atlanta (GA): Centers for Disease Control and Prevention; 2011. Available from URL: http://www.cdc.gov/violenceprevention/pdf/understanding_evidence-a. pdf (Accessed 13 June 2014).

67. Scutchfield FD, Lawhorn N, Ingram R, Perez DJ, Brewer R, Bhandari M. Public health systems and services research: dataset development, dissemination, and use. Public Health Rep. 2009;124:372-7. Available from URL: http:// www.ncbi.nlm.nih.gov/pmc/articles/PMC2663872/ (Accessed 13 June 2014).

68. Scutchfield FD, Ingram R. Public health systems and services research: building the evidence base to improve public health practice. Public Health Rev. 2014;35: epub ahead of print. Available from URL: http://www.public healthreviews.eu/show/a/126 (Accessed 13 June 2014).

69. Christakis NA, Fowler JH. The collective dynamics of smoking in a large social network. N Engl J Med. 2008;358:2249-58. Available from URL: http:// www.nejm.org/doi/full/10.1056/NEJMsa0706154 (Accessed 13 June 2014).

70. Christakis NA, Fowler JH. The spread of obesity in a large social network over 32 years. N Engl J Med. 2007;357:370-9. Available from URL: http://www. nejm.org/doi/full/10.1056/NEJMsa066082 (Accessed 13 June 2014).

71. Ben-Shlomo Y, Kuh D. A life course approach to chronic disease epidemiology: conceptual models, empirical challenges and interdisciplinary perspectives. Int J Epidemiol. 2002;31:285-93. Available from URL: http://ije.oxford journals.org/content/31/2/285.full (Accessed 13 June 2014).

72. Orton L, Lloyd-Williams F, Taylor-Robinson D, O'Flaherty M, Capewell S. The use of research evidence in public health decision making processes: systematic review. PLoS One. 2011;6:e21704. Available from URL: http:// dx.plos.org/10.1371/journal.pone.0021704 (Accessed 13 June 2014).

73. Pawson R, Greenhalgh T, Harvey G, Walshe K. Realist review--a new method of systematic review designed for complex policy interventions. J Health Serv Res Policy. 2005;10 Suppl 1:21-34.

74. Pawson R, Tilley N. Realist evaluation. In: DPRN thematic meeting 2006 report on evaluation. Utrecht (NL): Development Policy Review Network; 2008:35.

75. ResearchImpact. FAQs. ResearchImpact; 2014. Available from URL: https:// web.archive.org/web/20131009082432/http://researchimpact.ca/faqs/index. html (Accessed 13 June 2014).

76. Hartsfield D, Moulton AD, McKie KL. A review of model public health laws. Am J Public Health. 2007;97:S56-61. Available from URL: http://www.ncbi. nlm.nih.gov/pmc/articles/PMC1854995/ (Accessed 13 June 2014).

77. Mitton C, Adair CE, McKenzie E, Patten SB, Waye Perry B. Knowledge transfer and exchange: review and synthesis of the literature. Milbank Q. 2007;85:729-68. Available from URL: http://www.ncbi.nlm.nih.gov/pmc/ articles/PMC2690353/ (Accessed 13 June 2014). 
78. Jacobs JA, Dodson EA, Baker EA, Deshpande AD, Brownson RC. Barriers to evidence-based decision making in public health: a national survey of chronic disease practitioners. Public Health Rep. 2010;125:736-42. Available from URL: http://www.ncbi.nlm.nih.gov/pmc/articles/PMC2925010/ (Accessed 13 June 2014).

79. Heath GW, Parra DC, Sarmiento OL, Andersen LB, Owen N, Goenka S, et al. Evidence-based intervention in physical activity: lessons from around the world. Lancet. 2012;380:272-81.

80. World Health Organization. Draft action plan for the prevention and control of noncommunicable diseases 2013-2020: Report by the Secretariat. Geneva (CH): World Health Organization; 2013. Available from URL: http://apps. who.int/gb/ebwha/pdf_files/EB132/B132_7-en.pdf (Accessed 13 June 2014).

81. Brownson RC, Bright FS. Chronic disease control in public health practice: looking back and moving forward. Public Health Rep. 2004;119:230-8. Available from URL: http://www.ncbi.nlm.nih.gov/pmc/articles/PMC 1497626/pdf/15158101.pdf (Accessed 13 June 2014).

82. Brownson RC, Chriqui JF, Stamatakis KA. Understanding evidence-based public health policy. Am J Public Health. 2009;99:1576-83. Available from URL: http://www.ncbi.nlm.nih.gov/pmc/articles/PMC2724448/ (Accessed 13 June 2014).

83. European Observatory on Health Systems and Policies. BRIDGE knowledge for health: publishable summary. Geneva $(\mathrm{CH})$ : World Health Organization; 2013. Available from URL: http://cordis.europa.eu/documents/document library/116284151EN6.pdf (Accessed 13 June 2014).

84. The Aspen Institute. Geneva policy dialogue series for reproductive health. Aspen (CO): The Aspen Institute; 2014. Available from URL: http://www. aspeninstitute.org/events/geneva-policy-dialogue (Accessed 13 June 2014).

85. World Health Organization. Discussion paper: intersectoral action on health: a path for policy-makers to implement effective and sustainable intersectoral action on health. Geneva (CH): World Health Organization; 2011. Available from URL: http://www.who.int/nmh/publications/ncds_policy_makers_to_ implement_intersectoral_action.pdf (Accessed 13 June 2014).

86. Goel V. Building Public Health Ontario: experience in developing a new public health agency. Can J Public Health. 2012;103:e267-9. Available from URL: http://journal.cpha.ca/index.php/cjph/article/view/3289/2655 (Accessed 13 June 2014)

87. Ooms G, Stuckler D, Basu S, McKee M. Financing the millennium development goals for health and beyond: sustaining the 'big push'. Global Health. 2010;6:17,8603-6-17. Available from URL: http://www.globalizationand health.com/content/6/1/17 (Accessed 13 June 2014).

88. Suhrcke M, Rocco L, McKee M. Health and economic development. In: Health: a vital investment for economic development in eastern Europe and central Asia. Brussels (BE): European Observatory on Health Systems and Policies; 2007. Available from URL: http://www.euro.who.int/_data/assets/pdf_ file/0003/74739/E90569.pdf?ua=1 (Accessed 13 June 2014). 
89. Stuckler D, Basu S, McKee M. Drivers of inequality in Millennium Development Goal progress: a statistical analysis. PLoS Med. 2010;7:e1000241. Available from URL: http://dx.plos.org/10.1371/journal.pmed.1000241 (Accessed 13 June 2014).

90. Asaria P, Chisholm D, Mathers C, Ezzati M, Beaglehole R. Chronic disease prevention: health effects and financial costs of strategies to reduce salt intake and control tobacco use. Lancet. 2007;370:2044-53.

91. World Health Organization, World Economic Forum. From burden to "best buys": reducing the economic impact of non-communicable diseases in low- and middle-income countries. Cologny/Geneva $(\mathrm{CH})$ : World Economic Forum; 2011. Available from URL: http://www3.weforum.org/docs/WEF_WHO_HE_ ReducingNonCommunicableDiseases_2011.pdf (Accessed 13 June 2014).

92. Sanchez MA, Vinson CA, Porta ML, Viswanath K, Kerner JF, Glasgow RE. Evolution of cancer control P.L.A.N.E.T.: moving research into practice. Cancer Causes Control. 2012;23:1205-12.

93. Greenhalgh T, Robert G, Macfarlane F, Bate P, Kyriakidou O. Diffusion of innovations in service organizations: systematic review and recommendations. Milbank Q. 2004;82:581-629. Available from URL: http://onlinelibrary.wiley. com/doi/10.1111/j.0887-378X.2004.00325.x/full (Accessed 13 June 2014).

94. Fafard P. Evidence and healthy public policy: insights from health and political sciences. Montreal (QC): National Collaborating Centre for Health Public Policy; 2008. Available from URL: http://www.ncchpp.ca/docs/Fafard Evidence08June.PDF (Accessed 13 June 2014).

95. Centers for Disease Control and Prevention. Health communication basics. Atlanta (GA): Centers for Disease Control and Prevention; 2011. Available from URL: http://www.cdc.gov/healthcommunication/healthbasics/whatishc. html (Accessed 13 June 2014).

96. Fresh fruit, hold the insulin. Sci Am. 2012:306;12.

97. World Health Organization, Government of South Australia. Adelaide statement on health in all policies: Moving towards a shared governance for health and well-being. Geneva (CH): World Health Organization; 2010. Available from URL: http://www.who.int/social_determinants/hiap_statement_who_sa_final. pdf (Accessed 13 June 2014).

98. Commission on Social Determinants of Health. Closing the gap in a generation: health equity through action on the social determinants of health: final report of the Commission on Social Determinants of Health. Geneva $(\mathrm{CH})$ : World Health Organization; 2008. Available from URL: http://whqlibdoc.who.int/ publications/2008/9789241563703_eng.pdf (Accessed 13 June 2014).

99. Rimal RN, Lapinski MK. Why health communication is important in public health. Bull World Health Organ. 2009;87:247-247a. Available from URL: http://www.who.int/bulletin/volumes/87/4/08-056713.pdf (Accessed 13 June 2014). 